\title{
Scutellaria barbata D. Don inhibits growth and induces apoptosis by suppressing IL-6-inducible STAT3 pathway activation in human colorectal cancer cells
}

\author{
QIQIN JIANG ${ }^{1,2 *}$, QIONGYU LI ${ }^{1 *}$, HONGWEI CHEN $^{1}$, ALING SHEN $^{1}$, \\ QIAOYAN CAI ${ }^{1,3}$, JIUMAO LIN ${ }^{1,3}$ and JUN PENG ${ }^{1,3}$ \\ ${ }^{1}$ Academy of Integrative Medicine; ${ }^{2}$ People's Hospital; ${ }^{3}$ Fujian Key Laboratory of Integrative Medicine on \\ Geriatrics, Fujian University of Traditional Chinese Medicine, Fuzhou, Fujian 350122, P.R. China
}

Received September 9, 2014; Accepted August 4, 2015

DOI: $10.3892 /$ etm.2015.2692

\begin{abstract}
One of the most critical cellular signal transduction pathways known to malfunction in colorectal cancer is the interleukin-6/signal transducer and activator of transcription 3 (IL-6/STAT3) pathway. Scutellaria barbata D. Don (SB) is well-known traditional medicine in China that targets STAT3 signaling, and it has long been used to treat various types of cancer; however, the precise mechanism of its antitumor activity remains largely unclear. In order to further elucidate this underlying mechanism, an ethanol extract of SB (EESB) in cancer treatment. The aim of the present study was to evaluate the effects of EESB on the IL-6-inducible STAT3 pathway. We tested the dose-response association between EESB, IL-6-induced proliferaion and apoptosis using an MTT assay, colony formation and flow cytometry analysis in vitro. In addition, caspase- 9 and caspase- 3 activation was determined using a colorimetric assay, the activity of IL-6-induced STAT3 pathway was evaluated using western blot analysis, and the expression levels of cyclin D1, cyclin-dependent kinase $4, \mathrm{Bcl} 2$ and $\mathrm{Bcl} 2$-associated $\mathrm{X}$ were determined using reverse transcription-polymerase chain reaction and western blot analysis. In the present study it was found that EESB could significantly inhibit the IL-6-mediated increase in STAT3 phosphorylation levels and transcriptional activity in HT-29 human colon carci-
\end{abstract}

Correspondence to: Dr Jiumao Lin or Dr Jun Peng, Academy of Integrative Medicine, Fujian University of Traditional Chinese Medicine, 1 Qiuyang Road, Fuzhou, Fujian 350122, P.R. China E-mail: jiumaolin@ hotmail.com

E-mail: pjunlab@hotmail.com

*Contributed equally

Key words: Scutellaria barbata D. Don, colorectal cancer, interleukin-6/signal transducer and activator of transcription 3 pathway, apoptosis, proliferation noma cells, resulting in the suppression of cell proliferation and the induction of apoptosis. In addition, treatment with EESB markedly inhibited the IL-6-induced upregulation of cyclin D1 and B-cell lymphoma-2, two key target genes of the STAT3 pathway. These results suggest that treatment with EESB could effectively inhibit the proliferation and promote the apoptosis of human colon carcinoma cells via modulation of the IL-6/STAT3 signaling pathway and its target genes.

\section{Introduction}

With an estimated annual incidence of $>1$ million new cases worldwide, colorectal cancer (CRC) is one of the most frequently occurring human malignant neoplasms. Approximately 1 in 3 individuals that develop CRC succumb to the disease (1). Studies have demonstrated that aberrant tyrosine phosphorylation, or activation of signal transducer and activator of transcription 3 (STAT3), acts as a regulator of tumorigenesis (2) and that the expression rates of STAT3 and phosphorylated- (p-)STAT3 in CRC tissues are significantly higher than those in adjacent normal intestinal mucosa tissues (3). Interleukin-6 (IL-6) is a proinflammatory cytokine that is primarily produced by the cells comprising the tumor microenvironment: Fibroblasts, myeloid cells and lymphoid cells. IL-6 plays a key role in promoting the proliferation and inhibition of apoptosis (4), as it binds to its receptor (soluble IL-6 receptor) and coreceptor (glycoprotein 130, or gp130), resulting in the activation of the associated Janus kinases (JAKs). Activated JAKs phosphorylate gp130, leading to the recruitment and activation of STAT3 (5). STAT3 is an important transcription factor that plays an essential role in cell survival and proliferation $(6,7)$. It is known that the overexpression of cyclin D1 and B-cell lymphoma-2 (Bcl-2), among others, mediated by the abnormal activation of IL-6/STAT3, leads to excessive cell proliferation and apoptosis resistance. This, in turn, may cause tumorigenesis.

Inhibition of STAT3 transcriptional activity has been demonstrated to increase the rate of apoptosis in cancer cells (8). STAT3 has therefore been validated as a novel anticancer drug target, and targeting the STAT3 signaling pathway is considered a novel and promising therapeutic strategy in the 
treatment of cancer (9). Despite advances in chemotherapy, a regimen of 5-fluorouracil, in combination with oxaliplatin and irinotecan, remains one of the most important treatments of CRC (10); however, the majority of patients with CRC develop drug resistance and fall subject to metastasis. This problem has resulted in an increased interest in natural medicines, with studies in cancer therapeutics revisiting traditional herbal medicines. A number of herbal extracts or mixtures based on traditional medicines have exhibited anticancer effects with fewer or no side effects as compared with other anticancer therapeutics, including chemical compounds and targeting antibodies (11-13).

Scutellaria barbata D. Don (SB) is an important component of numerous medicinal formulas that have traditionally been used in China to treat a range of types of cancer, including CRC. We have recently reported that ethanol extract of SB (EESB) can exert numerous effects: i) Induction of cancer cell apoptosis by activating the mitochondrion-dependent pathway; ii) inhibition of tumor angiogenesis via suppression of Hedgehog signaling; and iii) induction of G1/S arrest in human colon carcinoma cells by modulating a number of signaling pathways associated with the cell cycle (14-17). In order to further elucidate the mechanism underlying the tumoricidal activity of EESB, the aim of the present study was to explore its effects on the IL-6-mediated activity in HT-29 human carcinoma cells, including cell proliferation and apoptosis, the STAT3 phosphorylation level and transcriptional activity, and the expression of a number of target genes of the IL-6/STAT3 signaling pathway.

\section{Materials and methods}

Materials and reagents. Dulbecco's modified Eagle's medium (DMEM), fetal bovine serum (FBS), penicillin-streptomycin, trypsin-EDTA, TRIzol ${ }^{\circledR}$ reagent, and caspase-9 and caspase-3 activation kits were purchased from Invitrogen (Life Technologies, Carlsbad, CA, USA). Monoclonal antibodies against $\mathrm{Bcl}-2$, Bcl2-associated $\mathrm{X}$ protein (Bax), cyclin D1 and cyclin-dependent kinase 4 (CDK4) and horseradish peroxidase (HRP)-conjugated secondary antibodies were obtained from Cell Signaling Technology, Inc. (Beverly, MA, USA). SuperScript $^{\mathrm{TM}}$ II reverse transcriptase was obtained from Promega Corp. (Madison, WI, USA). A bicinchoninic acid (BCA) protein assay kit was purchased from Tiangen Biotech (Beijing) Co., Ltd. (Beijing, China). Unless otherwise stated, all other chemicals were obtained from Sigma Chemical Co. (St. Louis, MO, USA).

Preparation of EESB. The original herb was collected in the Henan region of China and was identified as SB by Dr Wei $\mathrm{Xu}$ at the Department of Pharmacology, Fujian University of Traditional Chinese Medicine (Fuzhou, China). The plants were dried and cut into small pieces, and EESB was prepared as described in a previous study (16). Stock solutions of EESB were prepared by dissolving the EESB powder in $40 \%$ dimethyl sulfoxide (DMSO) to a concentration of $500 \mathrm{mg} / \mathrm{ml}$, and the solutions were stored at $-20^{\circ} \mathrm{C}$. The working concentrations of EESB were made by diluting the stock solution in the culture medium. The final concentrations of DMSO in the medium were $<0.5 \%$.
Cell culture. HT-29 human colon carcinoma cells were obtained from the Cell Bank of the Chinese Academy of Sciences (Shanghai, China). The cells were grown as an adherent monolayer in DMEM culture media containing $10 \%$ $\mathrm{v} / \mathrm{v}$ FBS, $100 \mathrm{U} / \mathrm{ml}$ penicillin and $100 \mu \mathrm{g} / \mathrm{ml}$ streptomycin in a humidified incubator at $37^{\circ} \mathrm{C}$ with $5 \% \mathrm{CO}_{2}$.

EESB and IL-6 treatment. HT-29 cells were cultured with DMEM containing $10 \%$ FBS and $1 \%$ penicillin/streptomycin. When the cells reached $50 \%$ confluence, the complete medium was changed with FBS-free medium overnight. The cells were then pretreated with various concentrations of EESB in complete DMEM for $1 \mathrm{~h}$, followed by stimulation with $10 \mathrm{ng} / \mathrm{ml}$ IL-6 (Sigma Chemical Co.) for the indicated periods.

Evaluation of cell viability by MTT assay. The cells were harvested and re-suspended at a final concentration of $1 \times 10^{5}$ cells $/ \mathrm{ml}$ and were seeded into a 96 -well plate at $100 \mu \mathrm{l} /$ well. Following incubation for $24 \mathrm{~h}$ at $37^{\circ} \mathrm{C}$, the cells were treated with different concentrations of EESB and/or IL-6 for another $24 \mathrm{~h}$. Subsequently, $100 \mu \mathrm{l} \mathrm{MTT}(0.5 \mathrm{mg} / \mathrm{ml})$ was added to each well. The plates were incubated at $37^{\circ} \mathrm{C}$ for $4 \mathrm{~h}$, and $100 \mu \mathrm{l}$ DMSO was added to dissolve the purple formazan crystals. The absorbance was then read at $570 \mathrm{~nm}$ with an ELISA reader (Model ELx800; BioTek Instruments, Inc., Winooski, VT, USA).

Observation of morphological changes. HT-29 cells were seeded into six-well plates in $2 \mathrm{ml}$ medium at a density of $2.5 \times 10^{5}$ cells/well. The cells were treated with various concentrations of EESB and/or IL-6 for $24 \mathrm{~h}$. The cell morphology was observed using a phase-contrast microscope (Leica, Solms, Germany). Images were captured at a magnification of $\mathrm{x} 200$.

Colony formation. HT-29 cells from the exponentially growing cultures were seeded into 12 -well culture plates at a density of $1 \times 10^{5}$ cells/well and treated with different concentrations of EESB and/or IL- 6 for $24 \mathrm{~h}$. The cells were then harvested and seeded into six-well plates at a final concentration of $1 \times 10^{3}$ cells/well in $2 \mathrm{ml}$ fresh medium. Following incubation for 8 days in a humidified incubator at $37^{\circ} \mathrm{C}$ with $5 \% \mathrm{CO}_{2}$, the formed colonies were fixed in $\mathrm{MeOH}-\mathrm{HAc}(3: 1, \mathrm{v} / \mathrm{v})$ for $10 \mathrm{~min}$, stained with crystal violet and counted. Cell survival was calculated by normalizing the survival of the control cells as $100 \%$.

Cell cycle analysis. A total of $2.5 \times 10^{5}$ HT-29 cells were seeded into six-well plates in $2 \mathrm{ml}$ medium and treated with the indicated concentrations of EESB and/or IL- 6 for $24 \mathrm{~h}$. The cells were harvested and adjusted to a concentration of $2 \times 10^{5}$ cells $/ \mathrm{ml}$. The HT-29 cell cycle progression was determined through flow cytometric analysis using a propidium iodide (PI) staining cell cycle assay kit (BD Biosciences, Franklin Lakes, NJ, USA). The cells were fixed in $70 \%$ ethanol at $4^{\circ} \mathrm{C}$ overnight. The fixed cells were washed twice with cold phosphate-buffered saline (PBS) and then incubated for $30 \mathrm{~min}$ with ribonuclease $(8 \mu \mathrm{g} / \mathrm{ml})$ and PI $(10 \mu \mathrm{g} / \mathrm{ml})$. The fluorescent signal was detected through the FL2 channel, and the proportion of DNA in various phases was analyzed using 
ModFit LT version 3.0 (Verity Software House, Inc., Topsham, ME, USA).

Detection of apoptosis through flow cytometric analysis with Annexin V/PI staining. A total of $2 \times 10^{5}$ HT- 29 cells were seeded into six-well plates in $2 \mathrm{ml}$ medium and treated with the indicated concentrations of EESB and/or IL- 6 for $24 \mathrm{~h}$. The apoptosis of the HT-29 cells was then determined through flow cytometric analysis using a fluorescence-activated cell sorter (FACSCalibur ${ }^{\mathrm{TM}}$; BD Biosciences) and an Annexin V-fluorescein isothiocyanate/PI kit (KeyGen Biotech, Nanjing, China). Staining was performed according to the manufacturer's instructions. In this assay, the Annexin V/PI double-negative population indicated viable cells, and the Annexin V-positive/PI-negative or Annexin V/PI double-positive populations represented cells undergoing early or late apoptosis, respectively.

Analysis of caspase-9/caspase-3 activation. Caspase-9 and caspase-3 activity was determined via a colorimetric assay using caspase- 9 and caspase- 3 activation kits, following the manufacturer's instructions (Invitrogen). Following treatment with various EESB concentrations and $10 \mathrm{ng} / \mathrm{mL}$ IL-6 for $24 \mathrm{~h}$, the HT-29 cells were lysed with the provided lysis buffer for $30 \mathrm{~min}$ on ice. The lysed cells were then centrifuged at $16,000 \mathrm{x}$ g for $10 \mathrm{~min}$. The protein concentration of the clarified supernate was determined, and $100 \mu \mathrm{g}$ protein was incubated with $50 \mu 1$ of the colorimetric tetrapeptide Leu-Glu-His-Asp-p-nitroaniline (pNA), a specific substrate of caspase-9, or with Asp-Glu-Val-Asp-pNA, a specific substrate of caspase- 3 , at $37^{\circ} \mathrm{C}$ in the dark for $2 \mathrm{~h}$. Samples were read at $405 \mathrm{~nm}$ in the ELISA reader. The data were normalized to the activity of the caspases in the control cells (treated with PBS vehicle) and were represented as the fold of control.

Reverse transcription polymerase chain reaction (RT-PCR) analysis. A total of $2 \times 10^{5}$ HT-29 cells were seeded into six-well plates in $2 \mathrm{ml}$ medium and treated with the indicated concentrations of EESB and/or IL-6 for $24 \mathrm{~h}$. The total RNA was isolated with TRIZol reagent. Oligo(dT)-primed RNA $(1 \mu \mathrm{g})$ was reverse-transcribed with SuperScript II reverse transcriptase according to the manufacturer's instructions (Promega Corp.). The obtained cDNA was used to determine the mRNA expression level of cyclin D1, (forward, 5'-TGG ATG CTG GAG GTC TGC GAG GAA-3' and reverse, 5'-GGC TTC GAT CTG CTC CTG GCA GGC-3', at $57^{\circ} \mathrm{C}$ ), CDK4 (forward, 5'-CAT GTA GAC CAG GAC CTA AGC-3' and reverse, 5'-AAC TGG CGC ATC AGA TCC TAG-3', at $58^{\circ} \mathrm{C}$ ), Bcl-2 (forward, 5'-CAG CTG CAC CTG ACG CCCTT-3 and reverse, 5'-GCC TCC GTT ATC CTG GAT CC-3', at $55^{\circ} \mathrm{C}$ ) and Bax (forward, 5'-TGC TTC AGG GTT TCA TCC AGG-3' and reverse, 5'-TGG CAA AGT AGA AAA GGG CGA-3', at $55^{\circ} \mathrm{C}$ ) by PCR analysis. GAPDH (forward, 5'-GT CAT CCA TGA CAA CTT TGG-3' and reverse, $5^{\prime}$-GA GCT TGA CAA AGT GGT CGT-3' at $58^{\circ} \mathrm{C}$ ) was used as a reference gene. The PCR cycling conditions for all sequences were as follows: 35 Cycles of denaturation at $95^{\circ} \mathrm{C}$ for $3 \mathrm{~min}$, annealing for $40 \mathrm{sec}$, and extension for $45 \mathrm{sec}$, and a final extension at $72^{\circ} \mathrm{C}$ for $10 \mathrm{~min}$. Samples were analyzed using gel electrophoresis (1.5\% agarose). The DNA bands were
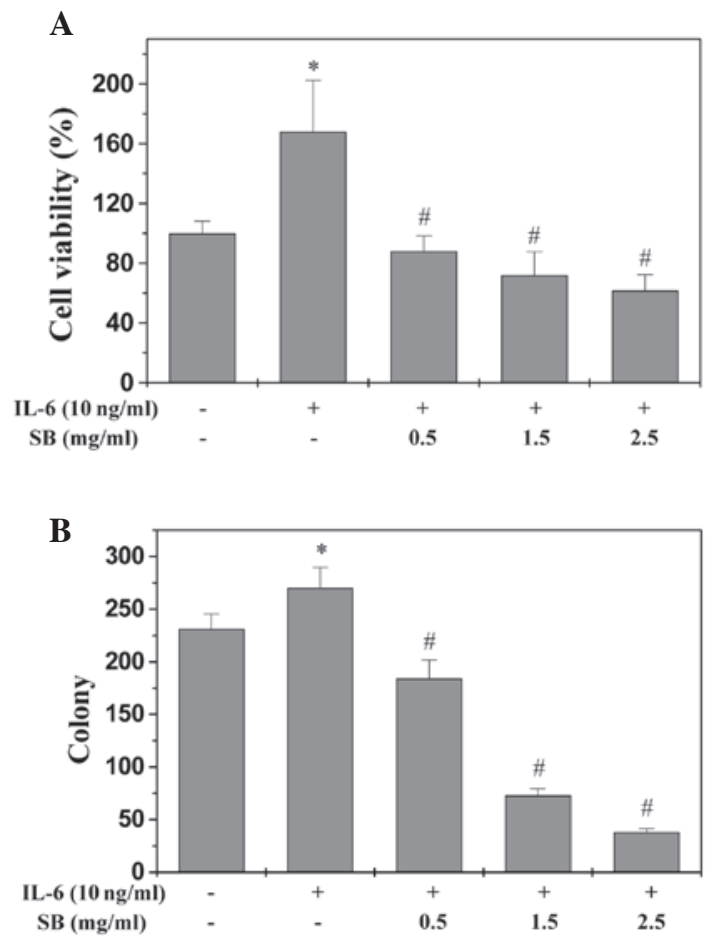

Figure 1. Effect of EESB on the proliferation of HT-29 cells. Cells were pretreated with various concentration of EESB for $1 \mathrm{~h}$, followed by stimulation with $10 \mathrm{ng} / \mathrm{ml} \mathrm{IL-6}$ for $24 \mathrm{~h}$. (A) Cell viability was determined by MTT assay. (B) Cell survival was evaluated by colony formation assay. The data were normalized to the viability or survival of control cells. ${ }^{*} \mathrm{P}<0.05$ vs. control cells; ${ }^{\text {} P}<0.05$ vs. cells treated with IL-6 but not EESB. EESB, ethanol extract of Scutellaria barbata D. Don; IL-6, interleukin-6.

examined using a gel documentation system (Gel Doc 2000; Bio-Rad Laboratories, Hercules, CA, USA).

Western blot analysis. HT-29 cells $\left(2 \times 10^{5} / \mathrm{ml}\right)$ were seeded into flasks and treated with the indicated concentrations of EESB and/or IL- 6 for $24 \mathrm{~h}$. The treated cells were lysed with mammalian cell lysis buffer containing different protein inhibitors. The total protein concentrations were determined via BCA assay. Equal quantities of protein from each cell lysate were subjected to SDS-PAGE and transferred onto polyvinylidene difluoride membranes. The membranes were blocked with $5 \%$ nonfat dry milk for $2 \mathrm{~h}$ and incubated with the desired primary antibody directed against p-STAT3, STAT3, cyclin D1, CDK4, Bcl-2, Bax and $\beta$-actin, at dilutions of 1:1,000, overnight at $4^{\circ} \mathrm{C}$. To image the antibody-detected proteins, the appropriate HRP-conjugated secondary antibodies with chemiluminescence detection were used.

Statistical analysis. All data are the means of three determinations and were analyzed using the SPSS package for Windows (version 17.0; SPSS, Inc., Chicago, IL, USA). Statistical analysis of the data was performed with a Student's t-test and analysis of variance. $\mathrm{P}<0.05$ was considered to indicate a statistically significant difference.

\section{Results}

EESB inhibits the growth of HT-29 cells. An MTT assay was used to determine the effect of EESB on HT-29 cell viability 

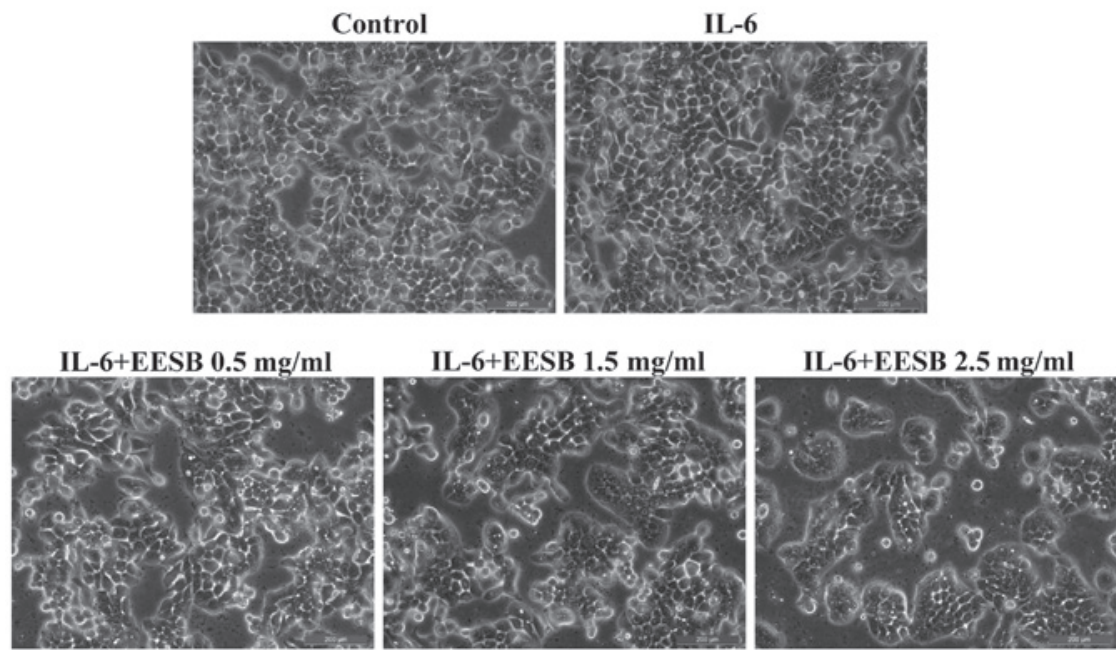

Figure 2. Observation of morphological changes of HT-29 cells treated with EESB. Cells were treated with various concentrations of EESB and/or IL-6 for $24 \mathrm{~h}$. The morphology of the cells was observed under a phase-contrast microscope. Images were captured at a magnification of x200. EESB, ethanol extract of Scutellaria barbata D. Don; IL-6, interleukin-6.

A
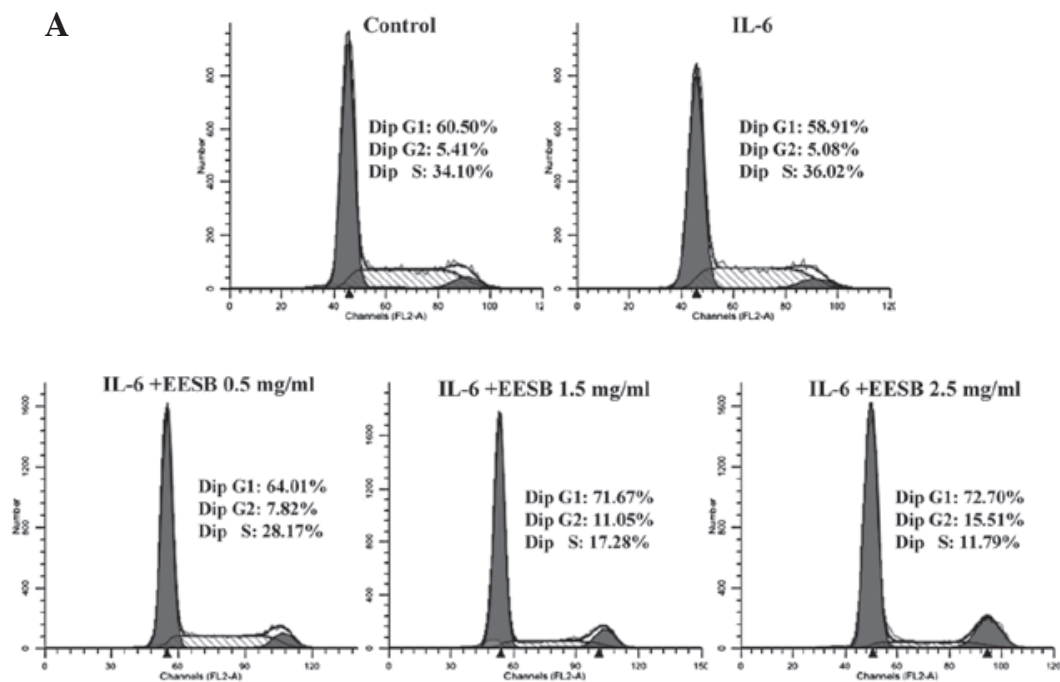

B

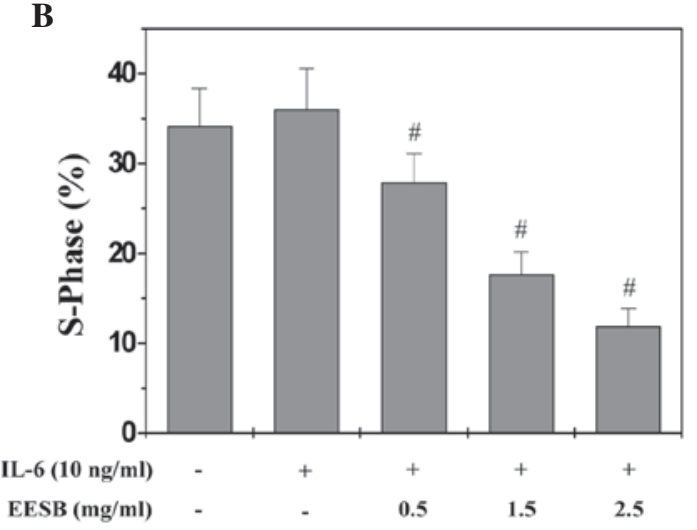

Figure 3. Effect of EESB on the HT-29 cell cycle. Cells were pretreated with various concentration of EESB for $1 \mathrm{~h}$, followed by stimulation with $10 \mathrm{ng} / \mathrm{m}$ IL-6 for 24 h. (A) Cells were stained with propidium iodide and analyzed by fluorescence-activated cell sorting. The proportion of DNA in the S phase was calculated using ModFit LT version 3.0 software. (B) Quantification of fluorescence-activated cell sorting analysis. The data shown are averages with standard deviation from 3 independent experiments. ${ }^{~ P}<0.05$ vs. cells treated with IL-6 but not EESB. EESB, ethanol extract of Scutellaria barbata D. Don; IL-6, interleukin-6.

in the presence of IL-6. As shown in Fig. 1A, IL-6 stimulation increased the viability of HT-29 cells to $167.89 \%$ compared with the control cells $(\mathrm{P}<0.05)$. Treatment with 0.5 to $2.5 \mathrm{mg} / \mathrm{ml}$ EESB for $24 \mathrm{~h}$ reduced the cell viability of the IL-6-stimulated cells from 88.06 to $61.72 \%(\mathrm{P}<0.05)$. Furthermore, the effect of EESB on HT-29 cell survival was examined using a colony formation assay. As shown in Fig. 1B, treatment with 0.5, 1.5 and $2.5 \mathrm{mg} / \mathrm{ml} \mathrm{EESB}$ for $24 \mathrm{~h}$ could reduce the survival rate of IL-6-stimulated cells by 20.35, 68.40 and $83.55 \%(\mathrm{P}<0.05)$, respectively. To further verify these results, the effect of EESB on HT-29 cell morphology was evaluated via phase-contrast microscopy, since the morphology of cells in culture is indicative of the healthy status of the cells. As shown in Fig. 2, it was found that EESB treatment dose-dependently reduced the density of the HT-29 cells. Taken together, these data demonstrate that EESB inhibits the growth of IL-6-stimulated HT-29 cells.
EESB blocks G1/S progression of HT-29 cells. G1/S transition is one of the two main checkpoints used by a cell to regulate the cell cycle progress and thus the proliferation of the cell. The effect of EESB on the G1 to S progression in HT-29 cells was therefore investigated via PI staining, followed by fluorescence-activated cell sorting analysis. As shown in Fig. 3, the percentage proportion of S-phase cells was $34.10 \%$ for the untreated control; $36.02 \%$ for the IL-6-stimulated HT-29 cells; and $28.17,17.28$ and $11.79 \%$ for the IL-6-stimulated HT-29 cells treated with various EESB concentrations $(0.5,1.5$ and $2.5 \mathrm{mg} / \mathrm{ml}$, respectively) $(\mathrm{P}<0.05)$. These results indicate that EESB inhibits the proliferation of HT-29 cells by blocking the G1- to S-phase progression of the cell cycle.

EESB induces apoptosis in HT-29 cells. To determine whether EESB could induce cell apoptosis, Annexin V/PI staining 
A
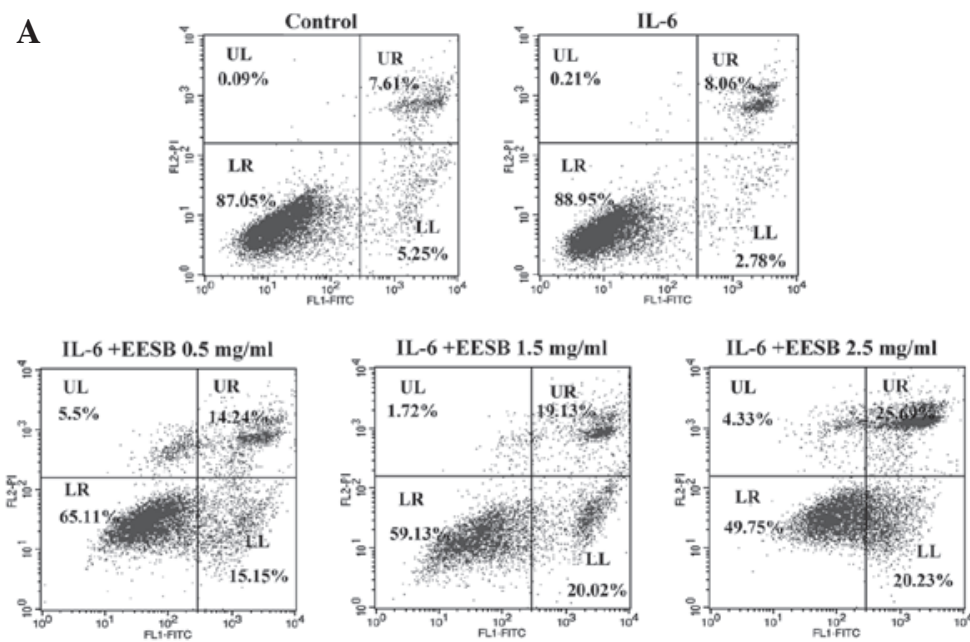

Figure 4. Effect of EESB on HT-29 cell apoptosis. Cells were pretreated with various concentration of EESB for $1 \mathrm{~h}$, followed by stimulation with $10 \mathrm{ng} / \mathrm{ml}$ IL-6 for 24 h. (A) Cells were collected and stained with Annexin V/PI, followed by fluorescence-activated cell sorting analysis. Double-negative stained cells indicate the live cell population; Annexin V-positive/PI-negative stained cells and Annexin V/PI double-positive stained cells represent early and late apoptosis, respectively; Annexin V-negative and PI-positive stained cells show dead cells. (B) Quantification of fluorescence-activated cell sorting analysis. The data shown are averages with standard deviation from 3 independent experiments. " $\mathrm{P}<0.05$ vs. cells treated with IL- 6 but not EESB. EESB, ethanol extract of Scutellaria barbata D. Don; IL-6, interleukin-6; UL, upper left; UR, upper right; LR, lower right; LL, lower left; PI, propidium iodide; FITC, fluorescein isothiocyanate.
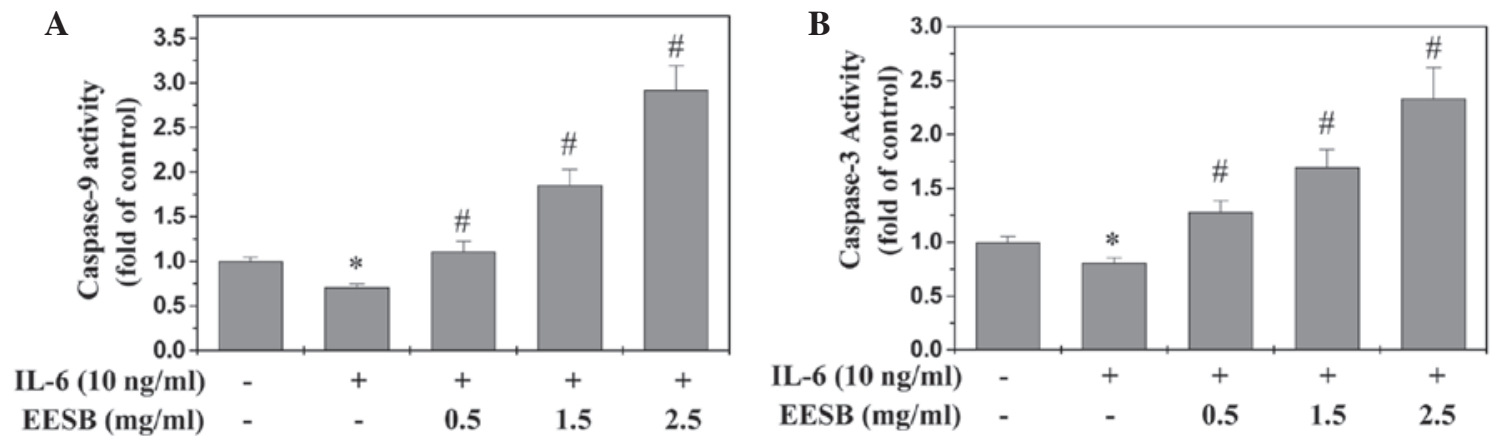

Figure 5. Effect of EESB on the activation of caspase-9/caspase-3. Cells were treated with the indicated concentration of EESB for $1 \mathrm{~h}$, followed by stimulation with $10 \mathrm{ng} / \mathrm{ml} \mathrm{IL-6}$ for $24 \mathrm{~h}$. (A) Caspase-9 and (B) caspase-3 activities were determined using a colorimetric assay. Data were normalized to the caspase activities within control cells and represented as the fold of control. "P<0.05 vs. control cells; ${ }^{\text {P }}<0.05$ vs. cells treated with IL- 6 but not EESB. EESB, ethanol extract of Scutellaria barbata D. Don; IL-6, interleukin-6.

with fluorescence-activated cell sorting analysis was used to examine the apoptosis of the HT-29 cells. As shown in Fig. 4A and B, the apoptosis of the HT-29 cells with stimulation of $10 \mathrm{ng} / \mathrm{ml}$ IL-6 was not significantly decreased compared with that of the control cells, which were not stimulated with IL-6 or EESB treatment $(\mathrm{P}>0.05)$; however, EESB treatment increased the percentage of cells undergoing apoptosis in a dose-dependent fashion $(\mathrm{P}<0.05$, as compared with the cells stimulated with IL-6 but not treated with EESB). In the FACS diagram, early apoptosis is shown in the lower-right quadrant and late apoptosis in the upper right.

EESB induces the activation of caspase- 9 and caspase- 3 in HT-29 cells. The activation of caspase- 9 and caspase- 3 was examined via colorimetric assay using a specific chromophore. Caspases, the cytoplasmic aspartate-specific cysteine proteases, are the key proteins in the apoptotic response. Caspase-9 can activate caspase-3 so that the specific and vital cellular proteins are targeted and degraded. Subsequently, the nuclear DNA degrades and the apoptotic death of the cells occurs;

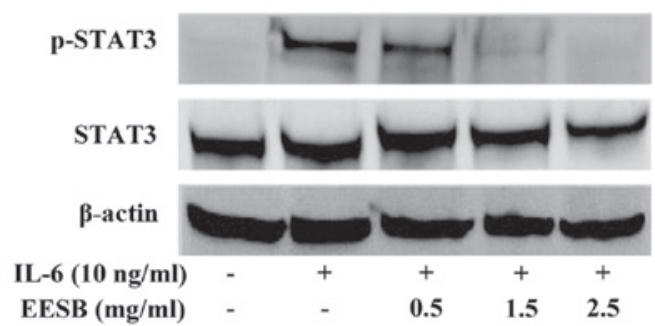

Figure 6. Effect of EESB on IL-6-mediated STAT3 phosphorylation in HT-29 cells. Cells were pretreated with various concentrations of EESB for $1 \mathrm{~h}$, followed by stimulation with $10 \mathrm{ng} / \mathrm{ml} \mathrm{IL}-6$ for $15 \mathrm{~min}$. STAT3 and STAT3 phosphorylation levels were determined by western blotting using an antibody recognizing phosphorylated STAT3 at Tyr705. $\beta$-actin was used as the internal control. EESB, ethanol extract of Scutellaria barbata D. Don; IL-6, interleukin-6; p-STAT3, phosphorylated-signal transducer and activator of transcription 3 .

therefore, the activation of caspases is important to the execution of apoptosis (14). As shown in Fig. 5, EESB treatment significantly and dose-dependently induced the activation of 

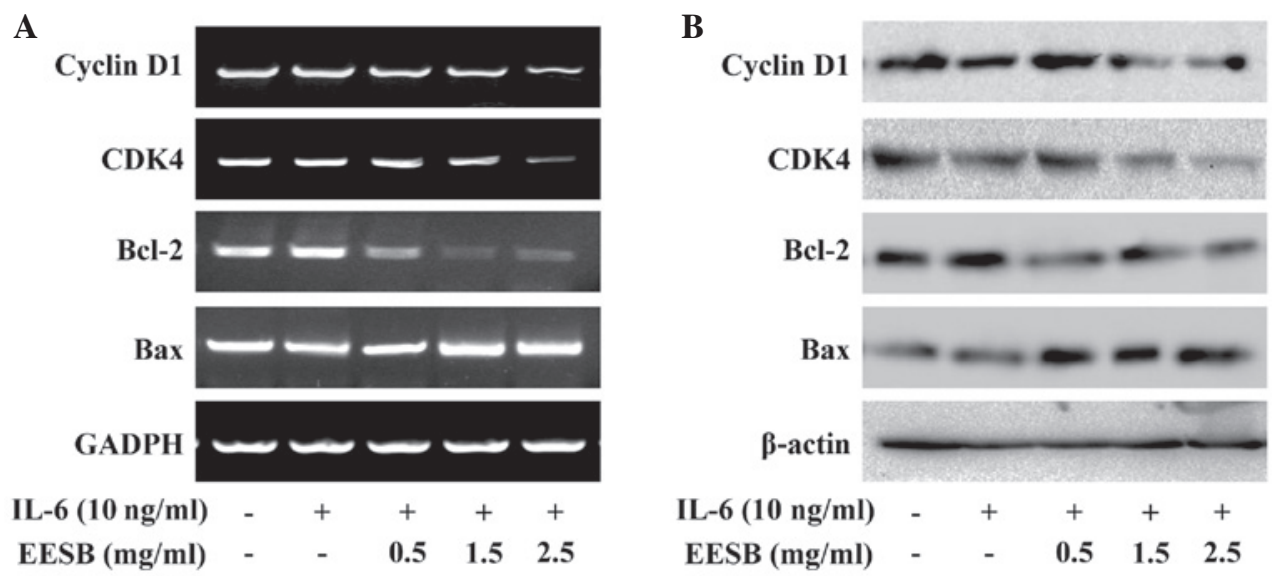

Figure 7. Effect of EESB on the expression of cyclin D1, CDK4, Bcl-2 and Bax. Cells were pretreated with various EESB concentrations for 1 h, followed by stimulation with $10 \mathrm{ng} / \mathrm{ml}$ IL-6 for $24 \mathrm{~h}$. (A) mRNA levels of cyclin D1, CDK4, Bcl-2 and Bax were determined using RT-PCR. (B) Protein expression levels of cyclin D1, CDK4, Bcl-2 and Bax were determined using western blot analysis. GAPDH and $\beta$-actin were used as the internal controls for the RT-PCR and western blot assay, respectively. EESB. EESB, ethanol extract of Scutellaria barbata D. Don; IL-6, interleukin-6; Bcl-2, B-cell lymphoma-2; Bax, Bcl2-associated X protein; CDK4, cyclin-dependent kinase 4; RT-PCR, reverse transcription polymerase chain reaction

both caspase- 9 and caspase- 3 in the HT-29 cells $(\mathrm{P}<0.01$, as compared with the cells stimulated with IL-6 but not treated with EESB). Additionally, IL-6 significantly inhibited the activation of caspase-9 and caspase-3.

EESB inhibits IL-6-mediated STAT3 activation in HT-29 cells. STAT3 activation was induced in the HT-29 cells via IL-6, as demonstrated in our previous report (18). Western blotting was performed to determine the phosphorylation level for STAT3 (p-STAT3) at Tyr705. As shown in Fig. 6, stimulation with IL-6 (10 ng/ml) significantly increased the level of p-STAT3, which was markedly inhibited by EESB in a dose-dependent manner. The level of non-phosphorylated STAT3 remained unchanged following treatment with IL-6 and/or EESB (Fig. 6).

EESB downregulates the expression of cyclin D1, CDK4, Bcl-2 and Bax in HT-29 cells. To further investigate the underlying mechanism of EESB in HT-29 cells, RT-PCR and western blot analyses were performed in order to examine the effect of EESB on the expression of the pro-proliferative cyclin D1 and CDK4, anti-apoptotic Bcl-2 and pro-apoptotic Bax, which are important target genes of the STAT3 signaling pathway. The results show that the mRNA and protein expression of cyclin D1, CDK4 and Bcl-2 was increased by IL-6 stimulation (Fig. 7); however, EESB treatment markedly inhibited the IL-6-induced upregulation of these genes at both the transcriptional and translational levels. The Bax mRNA and protein expression was decreased in the presence of IL- 6 and increased in IL-6-stimulated HT-29 cells treated with various concentrations of EESB.

\section{Discussion}

CRC is the second and third most commonly diagnosed malignancy in women and men, respectively, with 1.2 million individual diagnoses and $>600,000$ mortalities worldwide each year. Of these patients, $40-50 \%$ are likely to relapse or succumb despite the use of adjuvant chemotherapy $(1,19)$. CRC is a complex and heterogeneous condition that is associated with several cellular signal transduction pathways (20-23). As a result of this, the use of specific inhibitors that only target a single pathway in complex tumor systems may prove ineffective. Furthermore, the long-term administration of numerous single-target agents can lead to the development of drug resistance and unwanted side effects (24). SB is a major constituent of numerous traditional medicinal formulas in China that are used to treat a range of types of cancer, including CRC. Several traditional herbal medicines are composed of multiple natural compounds, including SB. Herbal medicines are thus considered to be multi-component and multi-target agents that exert their therapeutic functions in a more holistic manner (25).

Numerous studies have shown that STAT3 is constitutively activated in a diverse range of human tumors $(15,18)$. Furthermore, it has been suggested that aberrant STAT3 signaling can promote the initiation and progression of human cancer through either the inhibition of apoptosis or the induction of cell proliferation, angiogenesis, invasion and metastasis. The suppression of STAT3 activation is associated with the induction of tumor cell apoptosis (26). IL-6/STAT3 signaling regulates the survival and proliferation of intestinal epithelial cells and plays an important role in the pathogenesis of inflammatory bowel disease and CRC. The activation of the intracellular JAK/STAT3 signaling pathway, triggered by IL-6, leads to the induction of genes involved in the development of CRC (27). Cell proliferation is governed by the cell cycle, an order of events that is tightly regulated by a number of serine/threonine protein kinases known as CDKs and cyclins, such as CDK4 and cyclin D1 (28). Furthermore, Bax, Bcl-2 and the activation of caspase- 3 and caspase- 9 are involved in the apoptosis of CRC cells (29).

In the present study, HT-29 human colon carcinoma cells were stimulated with IL-6, and the rapid activation of STAT3 was observed. This led to a significant increase in the phosphorylation level and transcriptional activity of STAT3. The IL-6-mediated STAT3 activation was found to be markedly and dose-dependently inhibited by EESB treatment. Furthermore, 
EESB treatment significantly inhibited the mRNA and protein expression of Bcl-2, cyclin D1 and CDK4. The EESB-induced inhibition of the IL-6-mediated STAT3 activation and of cyclin D1, CDK4 and Bcl-2 expression led to the suppression of HT-29 cell proliferation and the induction of cell apoptosis. Furthermore, EESB treatment increased the expression of Bax.

In conclusion, the results of the present study have shown that EESB can effectively inhibit the proliferation and promote the apoptosis of human colon carcinoma cells by modulating the IL-6/STAT3 signaling pathway and its target genes. Further studies should be performed in order to fully elucidate the molecular mechanism underlying the action of EESB in cancer treatment and to enable the development of more effective multi-target drugs for cancer therapy.

\section{Acknowledgements}

This study was sponsored by the Developmental Fund of Chen Keji Integrative Medicine (grant nos. CKJ2014013 and CKJ2015007), the Natural Science Foundation of Fujian Province of China (grant no. 2013J01333) and the Research Foundation of Fujian University of Traditional Chinese Medicine (grant no. X2012012).

\section{References}

1. Jemal A, Bray F, Center MM, Ferlay J, Ward E and Forman D: Global cancer statistics. CA Cancer J Clin 61: 69-90, 2011.

2. Minn AJ, Gupta GP, Siegel PM, Bos PD, Shu W, Giri DD, Viale A, Olshen AB, Gerald WL and Massagué J: Genes that mediate breast cancer metastasis to lung. Nature 436: 518-524, 2005.

3. Zhong B, Liu Q, Liu Y, Xiong X and Liu Y: Expressions of STAT3, p-STAT3 and E-cadherin in colorectal cancer and clinical implications. Zhonghua Wei Chang Wai Ke Za Zhi 17: 594-597, 2014 (In Chinese).

4. Landskron G, De la Fuente M, Thuwajit P, Thuwajit $C$ and Hermoso MA: Chronic inflammation and cytokines in the tumor microenvironment. J Immunol Res 2014: 149185, 2014.

5. Heinrich PC, Behrmann I,Haan S, Hermanns HM, Müller-Newen G and Schaper F: Principles of interleukin (IL)-6-type cytokine signalling and its regulation. Biochem J 374: 1-20, 2003.

6. Bromberg J and Darnell JE Jr: The role of STATs in transcriptional control and their impact on cellular function. Oncogene 19 2468-2473, 2000.

7. Aggarwal BB, Kunnumakkara AB, Harikumar KB, Gupta SR, Tharakan ST, Koca C, Dey S and Sung B: Signal transducer and activator of transcription-3, inflammation, and cancer: How intimate is the relationship? Ann NY Acad Sci 1171: 59-76, 2009

8. Lin Q, Lai R, Chirieac LR, Li C, Thomazy VA, Grammatikakis I, Rassidakis GZ, Zhang W, Fujio Y, Kunisada K, et al: Constitutive activation of JAK3/STAT3 in colon carcinoma tumors and cell lines: Inhibition of JAK3/STAT3 signaling induces apoptosis and cell cycle arrest of colon carcinoma cells. Am J Pathol 167: 969-980, 2005

9. Turkson J: STAT proteins as novel targets for cancer drug discovery. Expert Opin Ther Targets 8: 409-422, 2004.

10. Nielsen DL, Palshof JA, Larsen FO, Jensen BV and Pfeiffer P: A systematic review of salvage therapy to patients with metastatic colorectal cancer previously treated with fluorouracil, oxaliplatin and irinotecan +/- targeted therapy. Cancer Treat Rev 40: 701-715, 2014.
11. Wang S, Wu X, Tan M, Gong J, Tan W, Bian B, Chen M and Wang Y: Fighting fire with fire: Poisonous Chinese herbal medicine for cancer therapy. J Ethnopharmacol 140: 33-45, 2012.

12. Qi F, Li A, Inagaki Y, Gao J, Li J, Kokudo N, Li XK and Tang W: Chinese herbal medicines as adjuvant treatment during chemoor radio-therapy for cancer. Biosci Trends 4: 297-307, 2010.

13. Cheng HM, Li CC, Chen CY, Lo HY, Cheng WY, Lee CH, Yang SZ, Wu SL, Hsiang CY and Ho TY: Application of bioactivity database of Chinese herbal medicine on the therapeutic prediction, drug development, and safety evaluation. J Ethnopharmacol 132: 429-437, 2010.

14. Wei L, Chen Y, Lin J, Zhao J, Chen X, Xu W, Liu X, Sferra TJ and Peng J: Scutellaria barbata D. Don induces apoptosis of human colon carcinoma cell through activation of the mitochondrion-dependent pathway. J Med Plant Res 5: 1962-1970, 2011.

15. Lin J, Chen Y, Cai Q, Wei L, Zhan Y, Shen A, Sferra TJ and Peng J: Scutellaria barbata D. Don inhibits colorectal cancer growth via suppression of multiple signaling pathways. Integr Cancer Ther 13: 240-248, 2013.

16. Wei L, Lin J, Wu G, Xu W, Li H, Hong Z and Peng J: Scutellaria barbata D. Don induces G1/S arrest via modulation of p53 and Akt pathways in human colon carcinoma cells. Oncol Rep 29: 1623-1628, 2013.

17. Wei L, Lin J, Xu W, Cai Q, Shen A, Hong Z and Peng J: Scutellaria barbata D. Don inhibits tumor angiogenesis via suppression of Hedgehog pathway in a mouse model of colorectal cancer. Int J Mol Sci 13: 9419-9430, 2012.

18. Shen A, Chen Y, Hong F, Lin J, Wei L, Hong Z, Sferra TJ and Peng J: Pien Tze Huang suppresses IL-6-inducible STAT3 activation in human colon carcinoma cells through induction of SOCS3. Oncol Rep 28: 2125-2130, 2012.

19. Scurr M, Ladell K, Besneux M, Christian A, Hockey T, Smart K, Bridgeman H, Hargest R, Phillips S, Davies M, et al: Highly prevalent colorectal cancer-infiltrating $\mathrm{LAP}^{+} \mathrm{Foxp}^{3-} \mathrm{T}$ cells exhibit more potent immunosuppressive activity than Foxp ${ }^{3+}$ regulatory T cells. Mucosal Immunol 7: 428-439, 2014.

20. de Jong PR, Mo JH, Harris AR, Lee J and Raz E: STAT3: An anti-invasive factor in colorectal cancer. Cancers (Basel) 6: 1394-1407, 2014.

21. Sabatino L, Pancione M, Votino C, Colangelo T, Lupo A Novellino E, Lavecchia A and Colantuoni V: Emerging role of the $\beta$-catenin-PPAR $\gamma$ axis in the pathogenesis of colorectal cancer. World J Gastroenterol 20: 7137-7151, 2014.

22. Pandurangan AK: Potential targets for prevention of colorectal cancer: A focus on PI3K/Akt/mTOR and Wnt pathways. Asian Pac J Cancer Prev 14: 2201-2205, 2013.

23. Vaiopoulos AG, Athanasoula KC and Papavassiliou AG: NF-кB in colorectal cancer. J Mol Med Berl 91: 1029-1037, 2013.

24. Boos G and Stopper H: Genotoxicity of several clinically used topoisomerase II inhibitors. Toxicol Lett 116: 7-16, 2000.

25. Li L and Leung PS: Use of herbal medicines and natural products: An alternative approach to overcoming the apoptotic resistance of pancreatic cancer. Int J Biochem Cell Biol 53: 224-236, 2014.

26. Siveen KS, Sikka S, Surana R, Dai X, Zhang J, Kumar AP, Tan BK, Sethi G and Bishayee A: Targeting the STAT3 signaling pathway in cancer: Role of synthetic and natural inhibitors. Biochim Biophys Acta 1845: 136-154, 2014.

27. Yang X, Zhang F, Wang Y, Cai M, Wang Q, Guo Q, Li Z and Hu R: Oroxylin A inhibits colitis-associated carcinogenesis through modulating the IL-6/STAT3 signaling pathway. Inflamm Bowel Dis 19: 1990-2000, 2013.

28. Lim S and Kaldis P: Cdks, cyclins and CKIs: Roles beyond cell cycle regulation. Development 140: 3079-3093, 2013.

29. Lin J, Chen Y, Wei L, Chen X, Xu W, Hong Z, Sferra TJ and Peng J: Hedyotis diffusa Willd extracts induces apoptosis via activation of the mitochondrion-dependent pathway in human colon carcinoma cells. Int J Oncol 37: 1331-1338, 2010. 